\title{
Estela funeraria de cronología omeya aparecida en Madrid (308/921) ${ }^{1}$
}

\author{
Umayyad Funerary Inscription Appeared in Madrid \\ $(308 / 921)$
}

\author{
María Antonia Martínez-Núñez \\ Universidad de Málaga, España
}

El presente artículo tiene como objetivo la traducción y estudio de una estela funeraria aparecida en el centro histórico de Madrid. Contiene el epitafio de un varón fallecido en el año 308/921. Este epígrafe tiene un gran interés histórico por su cronología temprana y por ser la primera inscripción árabe del periodo andalusí que ha aportado Madrid.

Palabras clave: epigrafía funeraria; Madrid; al-Andalus.
The main aim of this article is the translation and study of a funerary inscription appeared in the historical centre of Madrid. It contains the epitaph of a man who died in the year $308 / 921$. This inscription has a big historical interest because of its early chronology and because of being the first Arabic stele of the Andalusian period found in Madrid.

Key words: Funerary Inscription; Al-Andalus; Madrid.

Este texto tiene como objetivo el estudio de una estela funeraria aparecida en Madrid en cuyo frente ostenta una inscripción árabe con el epitafio de un varón fallecido en las primeras décadas del siglo $\mathrm{IV} / \mathrm{X}^{2}$. La pieza fue encontrada hace unos 20 años tras el derribo de un edificio del centro de Madrid, en el barrio de la Almudena, en las inmediaciones del Palacio Real, y era propiedad de un particular residente en Ugena (Toledo) ${ }^{3}$. Recientemente ha sido adquirida, mediante

${ }^{1}$ Este artículo ha sido realizado en el marco del proyecto de I+D Materiales de Madinat al-Zahrā': Producción y circulación de bienes en al-Andalus (HAR2009-10011, subprograma HIST) y del estudio de la epigrafía omeya de al-Andalus.

2 Quiero agradecer al arqueólogo Luis Alejandro García García la remisión del material gráfico y de todos los datos necesarios para proceder al análisis de la pieza, así como a Manuel Retuerce que fue quien inicialmente se puso en contacto conmigo para solicitar mi colaboración.

${ }^{3}$ Los datos relativos al hallazgo de los que dispongo, transmitidos por el propietario de la lápida al arqueólogo Luis Alejandro García, no aportan mayor precisión. 
compra, para su conservación y exposición en el Museo Arqueológico Regional de la Comunidad de Madrid. Es el primer epígrafe árabe monumental de cronología andalusí que, por el momento, ha proporcionado la ciudad de Madrid.

\section{Descripción}

Se trata de una lápida rectangular con los lados verticales más largos (fig. 1), la tipología más habitual en al-Andalus, aunque excepcionalmente hay algunos ejemplares de forma apaisada, con mayor medida en los lados horizontales ${ }^{4}$. Está realizada en piedra caliza bastante blanda, exactamente es toba calcárea, también llamada travertino. La parte trasera es muy irregular y sin trabajar (fig. 2), lo que implica que su posición original en la sepultura no debía de ser exenta; es decir, hincada verticalmente en la cabecera, sino que hubo de estar embutida en alguna pared o murete asociado al enterramiento, como sucede en el caso de una estela funeraria de cronología califal, con fecha expresa del año 331/943, que fue hallada in situ en unas excavaciones realizadas en Orihuela (Alicante) ${ }^{5}$.

El epígrafe, en cúfico con talla en relieve, se distribuye en once renglones y está bordeado por un filete tallado también en relieve y algo más ancho en el lado horizontal inferior, en cuyo centro se ubica un último término labrado sobre el filete (fig. 3). El fondo de la inscripción, la parte rebajada con respecto a las letras y al filete de enmarque, presenta un tono rojizo que parece responder a algún tipo de tinte voluntario para resaltar la caligrafía. Esa misma coloración rojiza en la superficie de fondo presenta otra estela funeraria procedente asimismo de Orihuela, fechada en el año 335/946 ${ }^{6}$.

Sus medidas máximas son: $41 \mathrm{~cm}$ de altura x $26 \mathrm{~cm}$ de ancho y entre 9,9 y 4,2 cm de grosor. Las medidas del filete de enmarque son: entre 2 y $2,3 \mathrm{~cm}$ (superior), entre 0,6 y $0,8 \mathrm{~cm}$ (izquierdo), entre 1,5 y

${ }^{4}$ Barceló, La escritura árabe en el país valenciano. Inscripciones monumentales, vol. 1, p. 65; Aguirre Sádaba, "Epitafios hispanomusulmanes de Arjona", pp. 126-127, n 2; Martínez Núñez, "Estelas funerarias de época califal aparecidas en Orihuela (Alicante)", pp. 67-72, no 3; Martínez Núñez, "Estela funeraria de cronología califal aparecida en Mengíbar (Jaén)", p. 84.

5 Martínez Núñez, "Estelas funerarias de época califal”, pp. 61-66, nº 2.

${ }^{6}$ Martínez Núñez, "Estelas funerarias de época califal”, pp. 51-60, nº 1. 


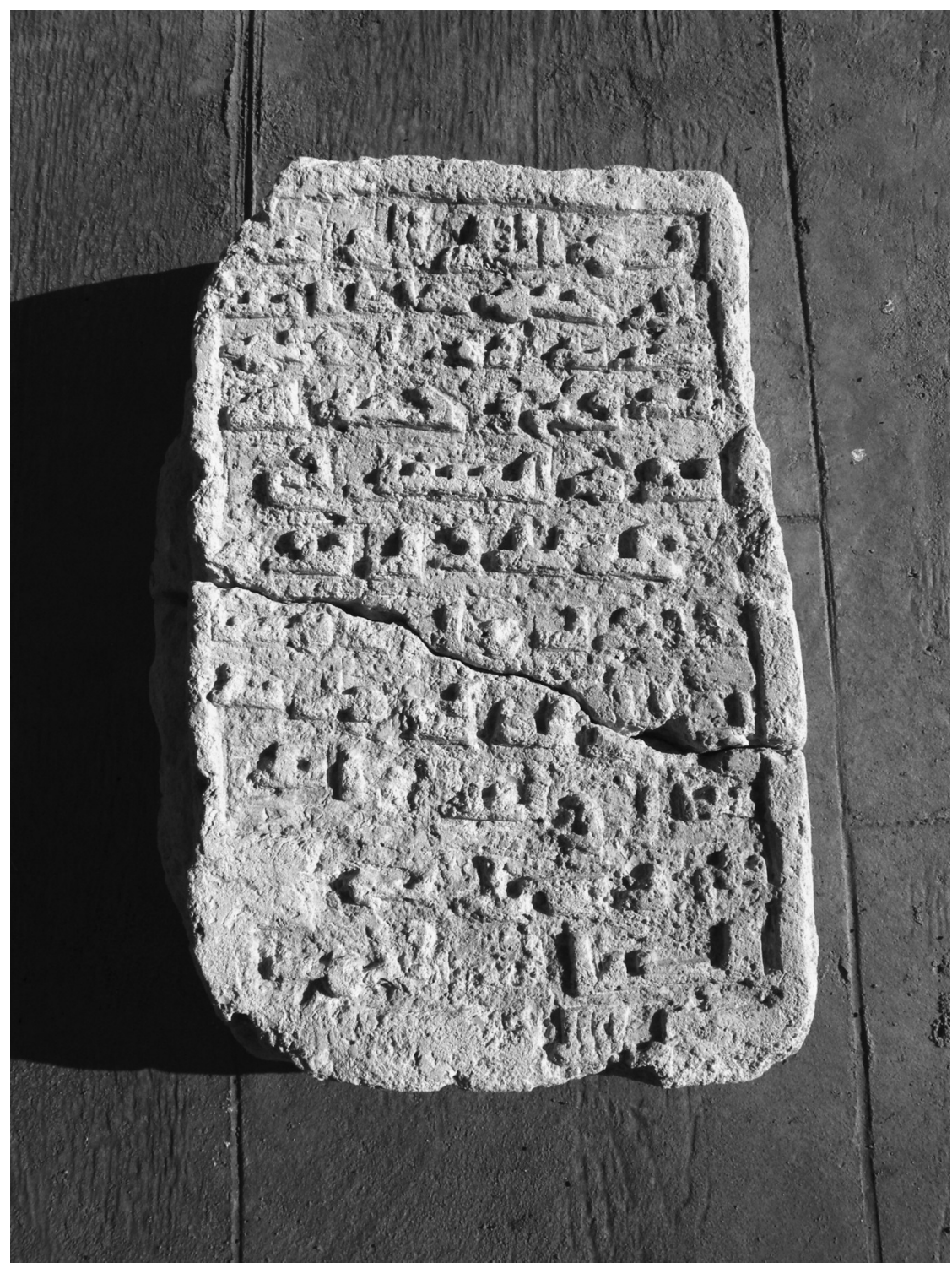

Figura 1. Vista frontal de la lápida. 


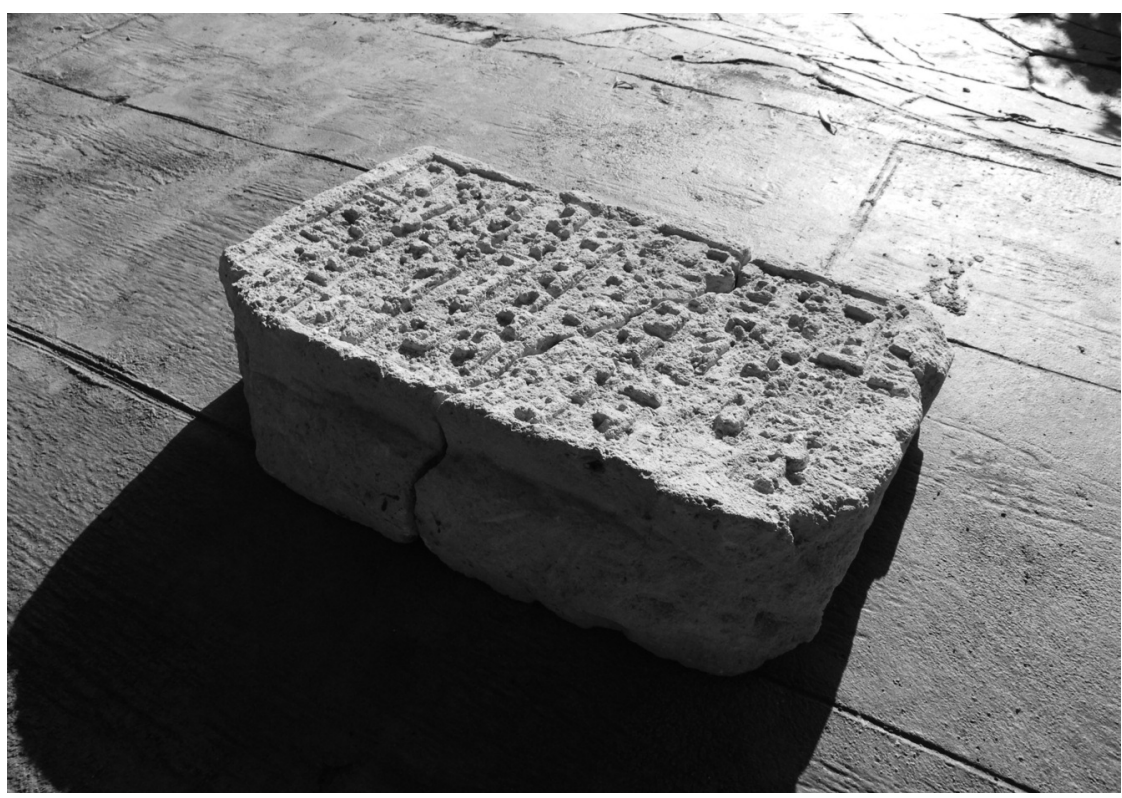

Figura 2. Detalle del grosor de la lápida y de la irregularidad de la parte trasera.

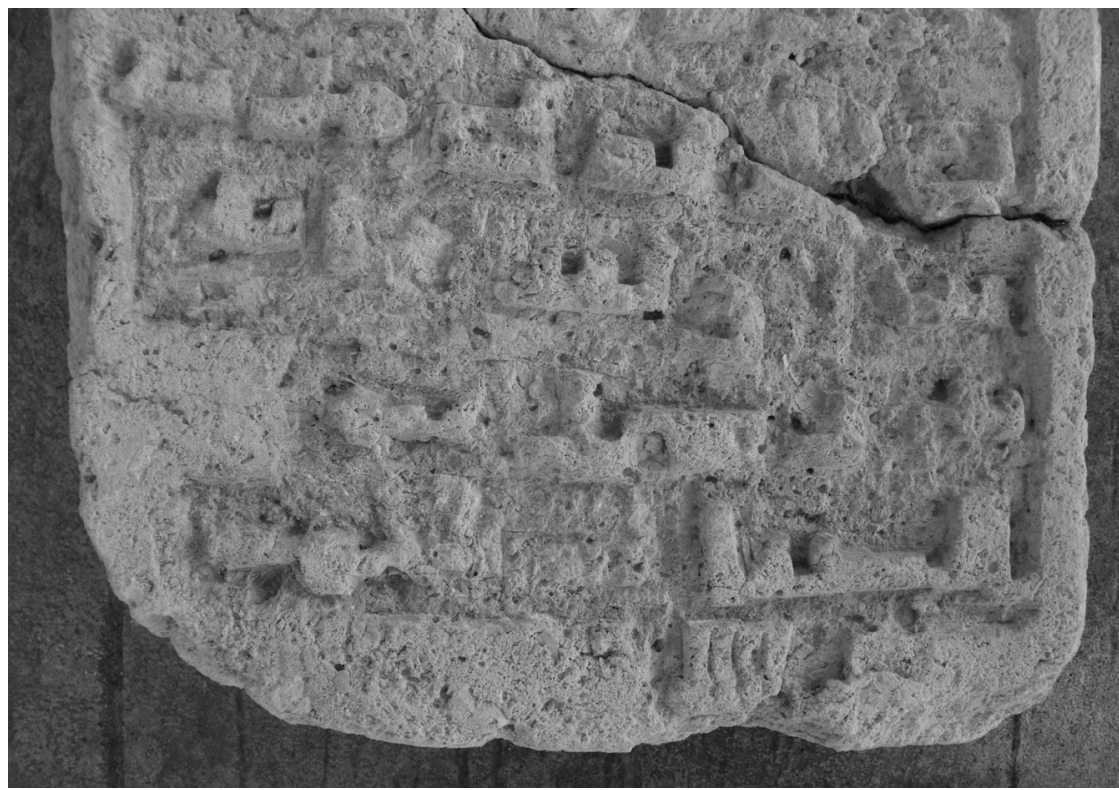

Figura 3. Detalle de la palabra escrita sobre el filete inferior. Al-Qantara XXXVI 1, 2015, pp. 141-163 ISSN 0211-3589 doi: 10.3989/alqantara.2015.005 
$1,8 \mathrm{~cm}$ (derecho) y entre 3 y 3,3 cm (inferior) (fig. 4). El módulo de la letra es de 2,5 cm. La altura del alif oscila entre los 1,5 cm del nombre Ibrāhìm en el tercer renglón y los $2,6 \mathrm{~cm}$ en el término al-Rahmān del primer renglón. El interlineado es bastante irregular, pues oscila entre la medida mínima de $1 \mathrm{~cm}$, entre los renglones $1^{\circ}$ y $2^{\circ}$, y la máxima de $2,6 \mathrm{~cm}$ existente entre los renglones $9^{\circ}$ y $10^{\circ}$, pasando por $\operatorname{los} 2 \mathrm{~cm}$ entre los renglones $6^{\circ}$ y $7^{\circ}$.

En cuanto al estado de conservación, la estela se encuentra bastante deteriorada, pues está partida en dos fragmentos que casan entre sí y presenta diversas fracturas en el filete de enmarque, especialmente en el ángulo superior izquierdo. El campo epigráfico se conserva completo, a pesar del deterioro que se observa en algunas partes del epígrafe, que afecta de manera especial a los tres últimos renglones, y del desgaste en el relieve de los grafemas, lo que dificulta la lectura del epígrafe. No obstante, se han podido restablecer la lectura y la traducción completas del epitafio.

\section{ESQUEMA DE MEDIDAS}
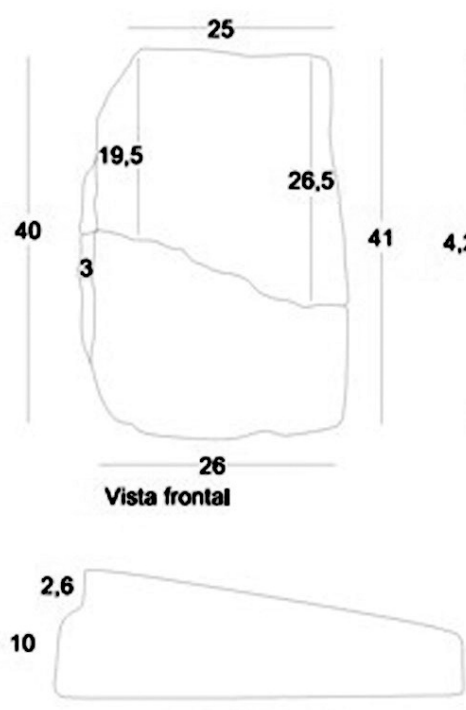

Sección general
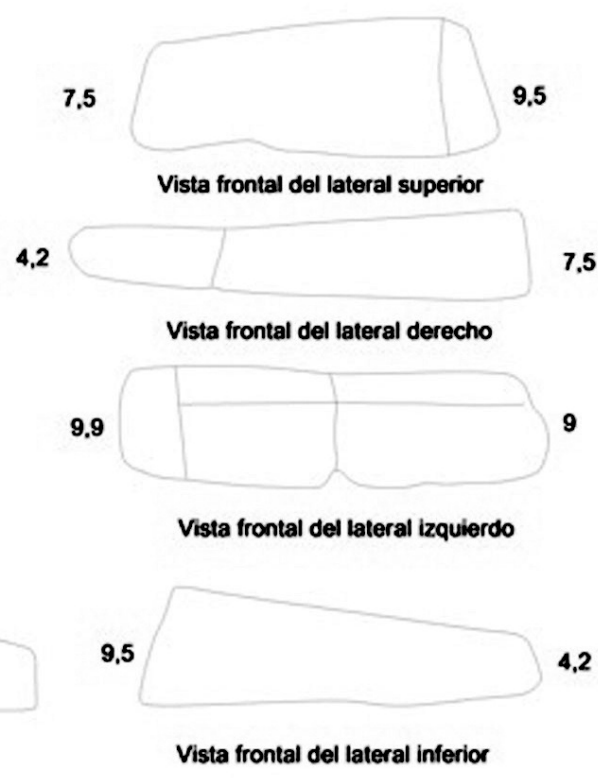

Figura 4. Medidas de la estela funeraria. Luis Alejandro García García. 


\section{Lectura y traducción de la inscripción}

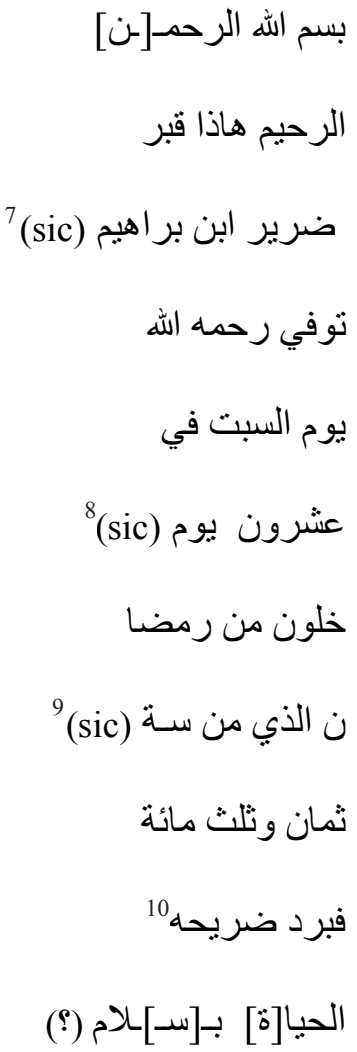

11 الله

7 Por ابر اهيم.

${ }^{8}$ Por عشرين يو اهيما.

9 Por falta de espacio se ha escrito de forma incompleta el término سنة

10 Este penúltimo renglón se encuentra deteriorado, pero creo que los trazos conservados no permiten otra lectura que la que ofrezco, a pesar de que se ha suprimido el sujeto de esta oración, Allāh .

${ }^{11}$ Lo que está grabado en el centro del filete inferior son cuatro trazos verticales, que deben corresponder al término Allāh. Aunque con todas las reservas, debido al gran deterioro del último renglón y a la forma en que se han tallado los términos que componen esta última parte de la inscripción, pues presenta anomalías de grafía, creo que esta lectura es la que puede darse al renglón $11^{\circ}$. 
En el nombre de Dios, el Clemente, el Misericordioso. Este es el sepulcro de Darīr ${ }^{12}$ b. Ibrāhīm.

Murió, Dios tenga misericordia de él, el diurno del sábado, a

veinte días pasados de ramaḍān, que fue del año ocho y trescientos (20 de ramaḍān del 308/2 de febrero del 921), y refresque (Dios) su tumba.

La vida está en la paz de

Dios (¿?)

\section{Análisis caligráfico}

El tipo de grafía utilizado es el cúfico arcaico con talla en relieve, en el que destaca la absoluta rigidez de la línea de base de escritura y un deficiente planteamiento previo del texto, lo que se proyecta en la irregularidad de su distribución entre renglones, en el encabalgamiento de algunas letras sobre el filete de enmarque (el mim de al-Rahmān en el renglón $1^{\circ}$ y el de yawm en el renglón $6^{\circ}$, el tầ marbùta de sana en el $8^{\circ}$ y el término Allāh sobre el filete inferior) y en la supresión del grafema final en algunos términos (el nün de al-Rahmān en el renglón $1^{\circ}$, parcialmente el $r \bar{a}$ ' de $q a b r$ en el renglón $2^{\circ}$ y el alif de ramadạn en el renglón $7^{\circ}$ y la escritura incompleta de sana en el renglón $8^{\circ}$ ) (fig. 5) ${ }^{13}$.

12 Aunque la lectura del ism del difunto es bastante segura, pues responde a la secuencia consonántica con que se inicia el tercer renglón, siempre caben variaciones debido a la polifonía de los grafemas cúficos y las posibles alternancias vocálicas. Así, también podría vocalizarse como Durayyar, con esquema de diminutivo de Dirār, ism usado en la antigua onomástica árabe y documentado en al-Andalus, en el nombre del gobernador Abū l-Jatțār b. Dirār: Terés, "Antroponimia hispano-árabe (reflejada por las fuentes hispano-romances) (II parte)", p. 23, n 231. Me he decantado por esta opción de lectura, Darīir, un ism con esquema de adjetivo y con varios significados, entre ellos el de «hombre paciente», porque está documentada en Ibn Hazm, Yamharat ansāb al-'arab, p. 38, donde se consigna formando parte de la kunya Ábū Dariir. Aunque se trata de un nombre poco usual, al menos en al-Andalus.

${ }^{13}$ Este dibujo de la lápida y el siguiente, que reproduce su alfabeto, han sido realizados por Ángela Aparicio. 


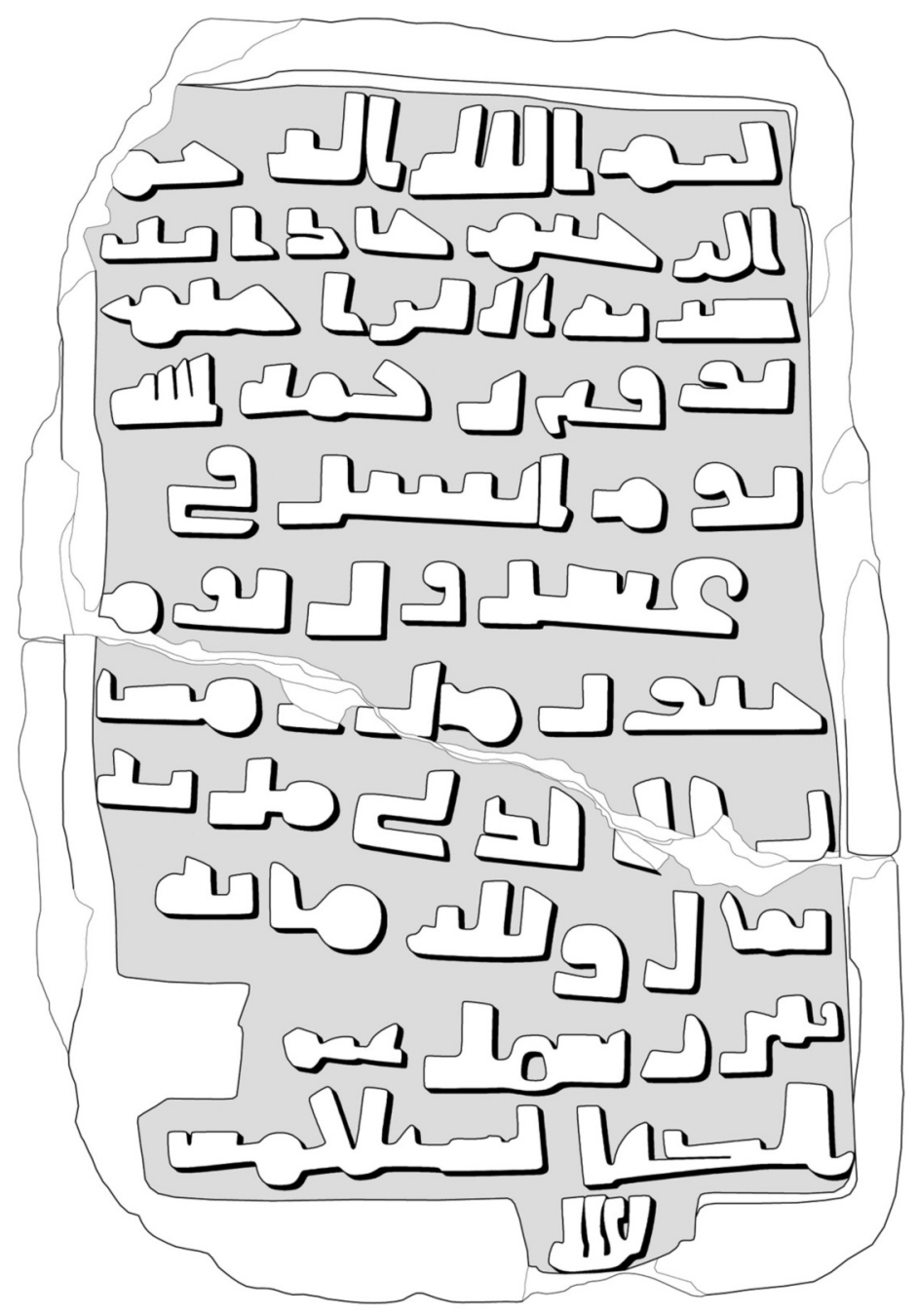

Vista frontal. E $1 / 2$

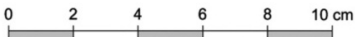

Figura 5. Dibujo de la inscripción (Ángela Aparicio). 
El cúfico arcaico absolutamente austero que presenta este ejemplar, sin ningún ornato ni estilización floral o foliada, es el tipo de escritura lapidaria usada durante el periodo emiral omeya en el siglo IX, ya desde los epígrafes más arcaicos de época del emir 'Abd al-Raḥmān II, y a principios del siglo $\mathrm{X}^{14}$, hasta la proclamación del califato en el año 316/929 y las innovaciones que trajo consigo en todos los ámbitos, incluido el epigráfico ${ }^{15}$. Pero, frente a las muestras de epigrafía emiral de Córdoba o de Mérida, inscripciones conmemorativas de fundaciones soberanas o estelas funerarias de mujeres vinculadas con los emires omeyas (las denominadas $\hat{y} a w \bar{a} r \bar{r})^{16}$, la grafía de esta lápida es de apariencia bastante más tosca y descuidada en su ejecución. Contribuye especialmente a esa impresión el escaso desarrollo en vertical de las astas y la macización del cuerpo de todos los grafemas, incluyendo el de $d \bar{a} d, f \bar{a} / q \bar{a} f, m \bar{i} m, w \bar{a} w$ o el de $h \bar{a}$ ' (fig. 6).

Así, en lo relativo a la grafía, hay que destacar la igualación en la altura de los grafemas 1a, 1f (alif aislado y final) y $12 \mathrm{i}$ y $12 \mathrm{~m}$ (lām inicial y medial) con la de $2 \mathrm{i}$ y $2 \mathrm{~m}(b \bar{a}, t \bar{a}, t \underline{a}, n \bar{u} n, y \bar{a}$ ' en posición inicial y medial) en algunos términos, como en al-Rahìm y en hād $\underline{a}$ (renglón $2^{\circ}$ ), y en Allāh (renglón $4^{\circ}$ ), o en jalūn (renglón $7^{\circ}$ ); es decir, que el asta del alif y del lām se acorta considerablemente hasta igualarse al diseño del signo cúfico 2 , al contrario de lo que sucede en la grafía más evolucionada a partir del califato, en el que la igualación entre la altura de esos grafemas cúficos se produce a partir del diseño del alif y el lām, proporcionando una mayor esbeltez al conjunto.

Asimismo, el vocablo Allāh (renglones $1^{\circ}, 4^{\circ}$ y en el filete inferior) y el nexo lām-alif $\left(\right.$ renglón $11^{\circ}$ ) tienen una factura mucho más rígida y tosca que la que suelen presentar en otros epígrafes de cronología emiral $^{17}$.

El trazado de algunos otros grafemas se asemeja, sin embargo, al que presentan epígrafes conmemorativos de fundaciones omeyas emi-

14 Ocaña Jiménez, El cúfico hispano y su evolución, pp. 22-29; Barceló, "Las inscripciones omeyas de la alcazaba de Mérida"; Martínez Núñez, "Epigrafía árabe e historia de al-Andalus: nuevos hallazgos y datos", pp. 42-44; Martínez Núñez, "Epigrafía funeraria en al-Andalus (siglos IX-XII)", pp. 183-187.

15 Ocaña Jiménez, El cúfico hispano y su evolución, pp. 30-35; Martínez Núñez, "La epigrafía del Salón de "Abd al-Rạ̣mān III", pp. 134-138.

${ }_{16}$ Martínez Núñez, "Mujeres y élites sociales en al-Andalus a través de la documentación epigráfica", pp. 314-316, 326-327.

${ }^{17}$ Ocaña Jiménez, El cúfico hispano y su evolución, pp. 47-48, figs. 9, 10. 


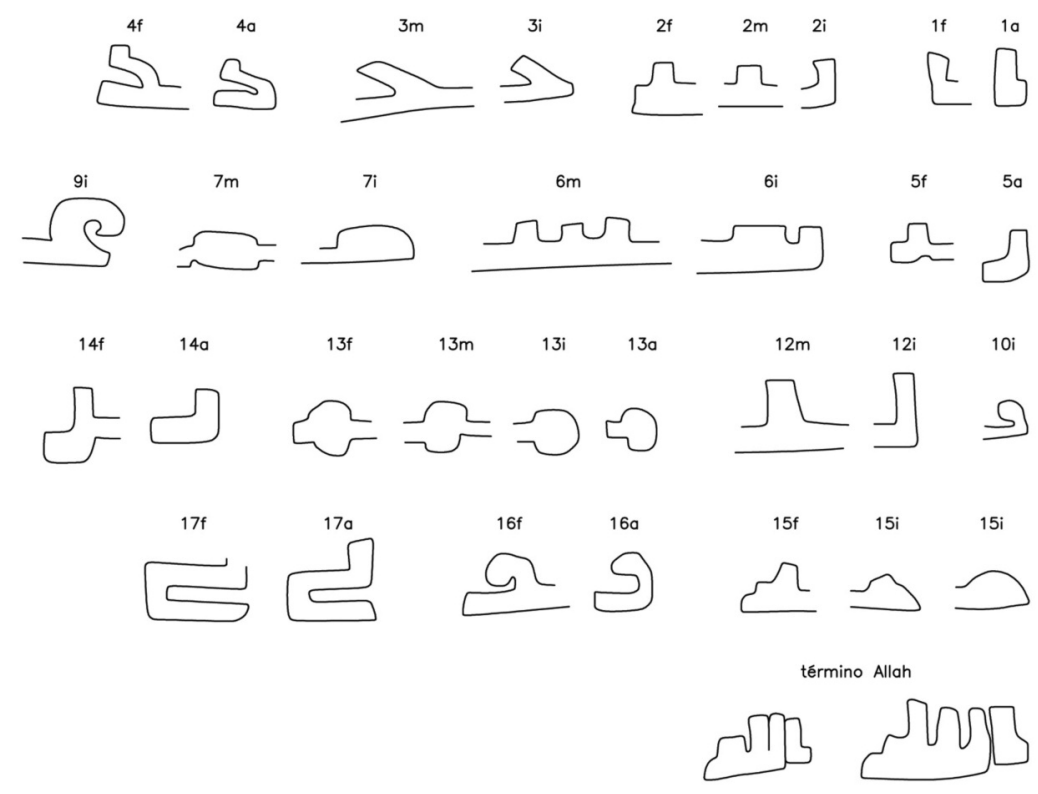

Figura 6. Alfabeto (Ángela Aparicio).

rales: 1$)$ el del grafema $4 \mathrm{a}$ y $4 \mathrm{f}(d \bar{a} l / \underline{d} \bar{a} l$ aislado y final) es semejante al de la inscripción fundacional de la alcazaba de Mérida ${ }^{18}$, salvo en el término barrada (renglón $10^{\circ}$ ), donde presenta una forma idéntica a la del grafema 5a (rā/zay aislado). 2) Igual sucede con el grafema $6 \mathrm{~m}$ ( $\sin / \operatorname{šn}_{i}$ medial), cuya forma en el término al-sabt (renglón $5^{\circ}$ ) es idéntica a la de la inscripción de Mérida y, sin embargo, presenta un diseño más compactado en el término 'išrūn (renglón $6^{\circ}$ ) y cuando aparece en posición inicial, en el término sana (renglón $8^{\circ}$ ). 3) Los grafemas 5 a y $5 \mathrm{f}\left(r \bar{a} / z a y\right.$ aislado y final), 9i ('ayn inicial) en 'išrūn (renglón $\left.6^{\circ}\right), 14 \mathrm{f}$ y $14 \mathrm{a}$ ( nūn final y aislado), identificado con el diseño de $5 \mathrm{f}$ y $5 \mathrm{a}, \mathrm{y} 17 \mathrm{f}$ ( $y \bar{a}$ ' final) son muy parecidos en su ejecución a los de la inscripción de Mérida, mientras que el grafema $13(\mathrm{mim})$, en todas sus posiciones, se parece al de Mérida en el trazado del cuerpo del grafema, pero en el epígrafe que nos ocupa se presenta macizado, sin el característico orificio central.

18 Ocaña Jiménez, El cúfico hispano y su evolución, p. 24, fig. 2. 
Esta inscripción presenta algunos rasgos particulares de grafía, como la forma compactada y muy tosca en que se ha ejecutado el grafema $7 \mathrm{i}$ y $7 \mathrm{~m}$ ( $s \bar{a} d / d \bar{a} d$ inicial y medial) en Darīr (renglón $3^{\circ}$ ), en $r a-$ madāan (renglón $7^{\circ}$ ) y en darìha-hu (rengón $10^{\circ}$ ), o la forma de $10 \mathrm{i}$ $\left(f \bar{a} / q \bar{a} f\right.$ inicial) en qabr (renglón $2^{\circ}$ ), en tuwuffiya (renglón $4^{\circ}$ ) y en $f a$ barrada (renglón $10^{\circ}$ ), apenas diferenciada de $2 \mathrm{i}$ al estar escasamente marcada la cabeza redondeada característica de esta letra, que además aparece macizada, sin el orificio central, e igual sucede con el grafema $16 a$ y $16 f$ ( $w \bar{a} w$ aislado y final), también macizado y con la parte circular superior apenas marcada. El $w \bar{a} w$ se ha trazado sobre la misma línea de escritura en los términos tuwuffiya (renglón $\left.4^{\circ}\right)$ y yawm $\left(5^{\circ}\right.$ y $6^{\circ}$ renglón), mientras que en wa-talat (renglón $9^{\circ}$ ) se ha escrito su apéndice final por debajo de la caja del renglón, como suele ser habitual, también en epígrafes de cronología emiral. El grafema $15 \mathrm{i}$ ( $h \bar{a}$ ' inicial), en $h \bar{a} \underline{d} \bar{a}$ (renglón $2^{\circ}$ ) y en $I b r a \bar{h} \bar{i} m$ (renglón $3^{\circ}$ ), tiene un diseño muy particular, macizado y con la parte superior apuntada, que se aparta del habitual para este grafema en epígrafes del emirato, igual sucede con este mismo grafema en posición final, cuyo diseño se aproxima en algún caso al de $2 \mathrm{f}$, como en rahima-hu (renglón $4^{\circ}$ ) y en el término Allāh (renglón $1^{\mathrm{o}}$ ).

Desde el punto de vista gramatical, se observa un único error en la mención de la fecha, cuando se ha escrito fi išrün yawm (renglones $5^{\circ}$ y $6^{\circ}$ ), en vez del correcto $f i$ 'išrin yawm ${ }^{a n}$ pues, aunque también resulta extraña la supresión del sujeto Allāh en la frase fa-barrada darīha-hu (renglón $10^{\circ}$ ), no puede considerarse como un error gramatical, ya que ese sujeto aparece consignado en una oración anterior, en rahima-hu Allāh (renglón $4^{\circ}$ ), y ambas oraciones se encuentran coordinadas mediante la conjunción $f a-$. Sin embargo, sí que parecen detectarse errores de grafía: la supresión del alif inicial en Ibrāhìm (renglón $3^{\circ}$ ) y especialmente la supresión de $t \bar{a}$ ' marbūta en al-ḥayāt y la unión del nexo lām-alif al mìm siguiente en bi-salàm, ambos en el renglón $11^{\circ}$, cuyo pésimo estado de conservación obliga a plantearlos con reservas. Todo lo demás son hechos habituales en grafía cúfica lapidaria andalusí, como es la separación entre renglones del término ramada $/ n$ (renglones $7^{\circ}$ y $8^{\circ}$ ), que se da siempre tras grafemas que no se unen al siguiente ${ }^{19}$, o la grafía defectiva, sin el alif de prolongación, en el numeral talat

19 Barceló, La escritura árabe en el país valenciano, vol.1, pp. 104-105. 
(renglón $9^{\circ}$ ), en vez de talät, mientras que sí se han escrito los alif/s de $h \bar{a} \underline{d} \bar{a}$ y de $m \bar{\imath}$ 'a términos que a veces se presentan con escritura defectiva en el registro epigráfico.

\section{Análisis textual}

El formulario de esta inscripción contiene los elementos fijos y fundamentales que suelen incluir los epitafios andalusíes desde sus manifestaciones más arcaicas en época emiral ${ }^{20}$, aunque el contenido que presenta alguno de ellos es ciertamente excepcional en epigrafía funeraria de al-Andalus.

El orden de los elementos que componen el formulario de este epígrafe son:
1. Basmala completa.
2. La expresión $h \bar{a} \underline{d} \bar{a} q a b r$.
3. Nombre del difunto.
4. El verbo tuwuffiya.
5. La expresión rahima-hu Allāh.
6. Fecha del óbito.
7. Eulogias de salida.

La basmala completa es la fórmula introductoria fija en los epitafios andalusíes y sólo a partir del siglo XIII empezó a emplearse la hamdala como elemento inicial ${ }^{21}$.

A esta fórmula introductoria le sigue la expresión hā $\underline{a} \bar{a}$ qabr («este es el sepulcro de») y a continuación el nombre del difunto. Esta secuencia es la habitual en epitafios andalusíes de cronología emiral ${ }^{22}$ y también en los de época califal, aunque en algunos epitafios de Córdoba, y en los de algunas provincias, se suele incluir tras la basmala completa la šahāda o alguna cita coránica ${ }^{23}$. La expresión $h \bar{a} d \bar{a} q a b r$ precede habitualmente al nombre del difunto en estelas funerarias andalusíes de cementerios urbanos, mientras que en los epitafios realiza-

${ }^{20}$ Barceló, La escritura árabe en el país valenciano, vol. 1, pp. 78-81; Martínez Núñez, "Epigrafía funeraria en al-Andalus", pp. 186-187.

${ }^{21}$ Barceló, "Estructura textual de los epitafios andalusíes (siglos IX-XIII)", p. 44.

${ }^{22}$ Ocaña Jiménez, El cúfico hispano y su evolución, pp. 23-26, n 3, 4, 5, 8.

23 Barceló, La escritura árabe en el país valenciano, vol. 1, pp. 126-128, 139-141; Martínez Núñez, "Estelas funerarias de época califal”, pp. 56-57, 65-66. 
dos en zonas rurales, así como en los fechados en el siglo XIII, se suele sustituir por la expresión tuwuffiya, o por wa-kāna wafātu- $h u^{24}$.

Sobre el nombre del difunto, un varón desconocido, se puede decir que se ha consignado un ism muy poco habitual en al-Andalus, Darìr (o el diminutivo Durayyar, como ya se ha apuntado) y el nasab ibn Ibrāhīm; datos muy escasos que no permiten identificarlo. La ausencia de nisba y de otros elementos habituales en la antroponimia medieval tampoco permite establecer su origen étnico. Sólo se puede apuntar como único indicio el hecho de que el ism Darīr, se encuentre documentado en la kunya de un árabe ${ }^{25}$.

El cuarto elemento del formulario es el verbo tuwufiyya («murió») que se consigna en la práctica totalidad de epitafios andalusíes, salvo en escasas ocasiones en que se sustituye por māta, como sucede en algunos ejemplares de Badajoz $^{26}$, por qutila («fue asesinado») o por istašhada («murió como mártir»), cuando el difunto fallece combatiendo en defensa del Islam ${ }^{27}$. El lugar que ocupa en esta lápida, inmediatamente detrás del nombre, se documenta en algún epitafio cordobés de cronología emiral, como el de Gadiira, una liberta del emir al-Ḥakam ${ }^{28}$, pero esta será la secuencia habitual en epitafios más tardíos del siglo XI y, sobre todo, a partir del siglo XII ${ }^{29}$.

La eulogia a favor del difunto rahima-hu Allāh («Dios tenga misericordia de él») es otro elemento fijo en los epitafios andalusíes de todas las épocas, y desde los ejemplares más arcaicos, y eso frente a la escasa fijeza que presentan los formularios de cronología omeya en Oriente ${ }^{30}$.

24 Barceló, "Estructura textual de los epitafios andalusíes", pp. 45-46.

${ }^{25}$ Como también pertenecen a la onomástica antigua árabe, Dirār y su diminutivo Durayyar; véase más arriba la nota 12 .

${ }^{26}$ Lévi-Provençal, Inscriptions arabes d'Espagne, p. 55, nº 44; Martínez Núñez, Epigrafia árabe. Catálogo del Gabinete de Antigüedades, pp. 79-80, n 18; Martínez Núñez, Epigrafía árabe del Museo Arqueológico de Badajoz, pp. 5-6, 22-23, nº 3 y no 10.

27 Barceló, "Estructura textual de los epitafios andalusíes", p. 48.

${ }^{28}$ Ocaña Jiménez, El cúfico hispano y su evolución, pp. 24-25, nº 4, lám. IV.

${ }^{29}$ Barceló, La escritura árabe en el país valenciano, vol. 1, pp. 84, 86.

${ }^{30}$ Especialmente en los graffiti, hasta el punto de que se suele hablar de la «libertad» en el uso de fórmulas religiosas, pues no se sabe si se aplican a personas vivas o ya fallecidas o probablemente a ambas; Ory, "Les graffiti umayyades de "Ayn Ğarr", p. 144; Ory, "Aspects religieux des textes épigraphiques du début de l'Islam”, pp. 30-39; Sourdel-Thomine, "Inscriptions et graffiti arabes d'époque umayyade", p. 119. Traté esta cuestión a propósito de las estelas funerarias de cronología califal aparecidas en Orihuela: Martínez Núñez, "Estelas funerarias de época califal”, pp. 59-60, notas 29 y 30. 
En al-Andalus esta expresión suele ir ubicada en dos posiciones: o tras el verbo tuwuffiya, como en el epitafio que nos ocupa, lo que suele ser poco usual en los epitafios de cronología omeya ${ }^{31}$, o tras el nombre del difunto, orden habitual en la mayor parte de los epitafios andalusíes hasta el final del califato omeya y en algunos de época taifa ${ }^{32}$.

El sexto elemento del formulario es la fecha del óbito que, como suele ser habitual en la epigrafía funeraria, proporciona una datación muy completa, pues se consigna el momento de la muerte, la feria de la semana, el día del mes y el año, aunque es preciso señalar que el diurno del 20 de ramadān del año 308, y su equivalente del 2 de febrero del año 921 del cómputo cristiano, no fue sábado, yawm al-sabt como está escrito en el epígrafe, sino viernes ${ }^{33}$. Sin embargo, al igual que sucede en la mayor parte de los epitafios andalusíes, no se consigna la fecha del nacimiento ni la edad del difunto, ya que estas precisiones sólo fueron de uso general en los epitafios de cronología tardía, durante la etapa nazarín ${ }^{34}$, aunque se documentan algunos casos más tempranos $^{35}$. Para la mención del año se ha usado el término sana, el comúnmente empleado en epigrafía andalusí, aunque a partir del siglo XI se sustituye a veces por 'àm, que es el término usado prioritariamente en los epitafios nazaríes ${ }^{36}$. Además, en este epitafio se ha utilizado para introducir la mención del año una oración de relativo, min ramadān alladì min sana... («de ramaḍ̂an que es del año...»), considerada por

31 Aunque hay algunos ejemplares de cronología emiral y califal en que se documenta esta misma secuencia, como en los fragmentos del epitafio de una mujer, probablemente una ŷâriya del emir 'Abd Allāh (m. 294/906), aparecidos en Córdoba: Ocaña Jiménez, El cúfico hispano y su evolución, p. $28, \mathrm{n}^{\circ} 8$, lám. VIII, o en dos de las estelas de cronología califal de Orihuela: Martínez Núñez, "Estelas funerarias de época califal”, pp. 56, 61, $\mathrm{n}^{\mathrm{o}} 1,2$.

32 Barceló, "Estructura textual de los epitafios andalusíes", p. 46; Barceló, La escritura árabe en el país valenciano, vol. 1, p. 80; Martínez Núñez, "Estelas funerarias de época califal”, p. 60; Martínez Núñez, Epigrafía árabe, pp. 78-79, n 17 y pp. 79-80, nº 18.

${ }_{33}$ Cuando se trata del diurno, coincide exactamente la feria semanal en el cómputo musulmán y en el cristiano, como afirma Ocaña Jiménez, Nuevas tablas de conversión, p. 39, por lo que debe de tratarse de un error en la mención de la feria semanal o del día del mes.

${ }^{34}$ Barceló, La escritura árabe en el país valenciano, vol. 1, p. 80.

${ }^{35}$ Como se observa en algunos ejemplares de Badajoz de los siglos XI, XII: Martínez Núñez, Epigrafía árabe del Museo Arqueológico de Badajoz, pp. 8-10, nº 5 y 6.

${ }^{36}$ Lévi-Provençal, Inscriptions arabes d'Espagne, p. XXII, nota 1; Barceló, "Estructura textual de los epitafios andalusíes", pp. 48-49. 
É. Lévi-Provençal como «expresión vulgarizante»y documentada en otros epitafios más tardíos, a partir del siglo $\mathrm{XI}^{37}$.

El formulario termina con unas frases de cierre, como suele ser habitual en epigrafía funeraria andalusí de época omeya ${ }^{38}$, aunque en algunos casos se suprime este elemento y el formulario termina con la mención de la fecha ${ }^{39}$. Las frases de salida contienen generalmente las denominadas «eulogias de relación», frases piadosas y estereotipadas de invocación a Dios a favor del difunto, de sus familiares o de los musulmanes, que se repiten con ligeras variantes en los epitafios de periodos cronológicos o áreas geográficas concretas ${ }^{40}$. Las reproducidas en esta estela son, sin embargo, escasamente utilizadas y resultan difíciles de interpretar no sólo por el gran deterioro del texto en los dos últimos renglones, sino también por su excepcionalidad, como se desprende de los grafemas que se han conservado, sea cual sea la restitución del texto y la lectura que se propongan.

En función de la lectura que he propuesto, dos son las eulogias con las que finaliza el formulario de este epitafio: fa-barrada (Allāh) darìha-hu y al-hayā(t) bi-salām Allāh que, como se ha dicho, son muy poco habituales en epitafios andalusíes y menos en los de cronología emiral. Una variante de fa-barrada Allāh darīha-hu se consigna en el epitafio de 'Izz al-Dawla, soberano de la taifa de Alpuente, fallecido en el año 447/1055, wa-barrada madŷa a-hu wa-nawwara darìha-hu («refresque su lugar de reposo e ilumine su tumba»), además de documentarse en ejemplares de otros territorios islámicos, como Dahlak o Egipto $^{41}$. En cuanto a la expresión al-hayāt bi-salām Allāh, que yo sepa es la primera vez que, por el momento, se ha documentado en epigrafía funeraria de al-Andalus, aunque su talante y su sentido (la vida eterna está en la salvación de Dios) se adapta bien al mensaje y al contenido de estas fórmulas funerarias. Así, tanto hayāt como salām son términos usados reiteradamente en el Corán, en cuyas aleyas se opone la vida terrenal (al-ḥayāt al-dunyà) a la vida eterna (al-hayāt al-äjira) (Q. III,

37 Lévi-Provençal, Inscriptions arabes d'Espagne, p. XXII, nota 1 y n ${ }^{\circ} 61,88,92$.

38 Barceló, "Estructura textual de los epitafios andalusíes", p. 49; Barceló, La escritura árabe en el país valenciano, vol. 1, pp. 80-81, 82.

39 Ocaña Jiménez, El cúfico hispano y su evolución, no 5, 8, 9; Martínez Núñez, "Estelas funerarias de época califal", pp. 60, 66, 72 .

${ }^{40}$ Barceló, "Estructura textual de los epitafios andalusíes", pp. 49-51.

${ }^{41}$ Barceló, La escritura árabe en el país valenciano, vol.1, pp. 84-85, 153-156, nº 17. 
185 y XXIX, 64, entre otros) y el término salām designa tanto la salud terrenal como la salud eterna o, en otras palabras, la salvación, y seguridad eternas que proporciona Dios, y de ahí la expresión dār al-salām ( «la morada de la salvación = el Paraíso»). Por otra parte, y al margen del registro epigráfico, son conocidas ciertas frases de un talante parecido: hayyā-ka Allāh («que Dios te haga vivir»), que es sinónimo de sallama ${ }^{42}$; es decir, que es otra modalidad de la tahiyyat al-islām («saludo islámico»), según se comprueba en Q. IV, 86, y hayyà Allāh waŷha-hu («que Dios conserve su rostro»).

\section{A modo de conclusión}

Esta estela funeraria presenta un enorme interés histórico por varias razones:

La primera de ellas, por el lugar de su hallazgo, en el centro histórico de Madrid, enclave que no había proporcionado hasta ahora ninguna inscripción árabe monumental de cronología andalusít ${ }^{43}$, puesto que el único epígrafe árabe que se conocía hasta el momento, un fragmento de alfiz de yeso hallado en las excavaciones de la Plaza de la Armería, pertenece a la etapa de dominio cristiano, posterior al momento en que Madrid pasa a manos del monarca Alfonso VI, con las negociaciones previas a la caída de Toledo en 1085. Por ello hay que relacionarla con una comunidad mudéjar o morisca ${ }^{44} \mathrm{y}$, por tanto, el

${ }^{42}$ Como se consigna en el Dictionnaire arabe-français de B. Kazimirski y expone Arendonk ("Salām", en $E I^{2}$, VIII, p. 947).

${ }^{43}$ Madrid sí había proporcionado omóplatos con alifatos y basmala: cuatro procedentes de Madrid capital (Doménech Belda y López Seguí, "Los alifatos sobre huesos", pp. 254-255) y uno de Alcalá de Henares, mencionado por Zozaya, "Os inscrit", p. 93, y que he tenido ocasión de leer y analizar recientemente a petición de este último autor, aunque la lectura permanece inédita.

${ }_{44}$ Así lo ha planteado Esther Andréu, en una reciente publicación sobre el valor de la arqueología para el conocimiento de la historia de Madrid (Andréu Mediero,"La arqueología como determinante para el conocimiento del origen de Madrid", p. 51). El fragmento de alfiz en yeso lleva pintada en negro una inscripción en caracteres cúficos que reproduce la expresión repetida al-mulk li-llāh («la soberanía pertenece a Dios») y ha sido fechada a finales del siglo XII o principios del XIII (p. 49). Aunque los rasgos gráficos de este fragmento de yesería pueden remitir a una horquilla cronológica más amplia, que oscilaría entre la etapa almorávide, finales del siglo XI y primera mitad XII, y la almohade, hasta primera mitad del s. XIII, esta muestra epigráfica seguiría remitiendo a una comunidad musulmana/mudéjar bajo dominio cristiano. 
único epígrafe conocido del Madrid andalusí es la lápida funeraria objeto del presente estudio.

En segundo lugar, esta lápida reviste un gran interés por su cronología muy temprana, de principios del siglo IV H., antes de la proclamación como califa del omeya 'Abd al-Raḥmān III en el año 316/929. Durante la etapa emiral y fuera de Córdoba, la capital de los omeyas, es realmente excepcional el uso de estelas funerarias en cementerios islámicos pues, como ponen de manifiesto los datos suministrados por diversas excavaciones arqueológicas, los enterramientos más antiguos de la etapa emiral carecían de estelas y de epitafios ${ }^{45}$. Las inscripciones más arcaicas y de seguro carácter funerario son escasas y proceden de dos núcleos urbanos muy concretos: la mayor parte de Córdoba y una sola de Pechina. Ninguno de estos ejemplares es anterior a la etapa del emir omeya 'Abd al-Raḥmān II (822-852) ${ }^{46}$. En cuanto a los años finales de la etapa emiral, a principios del siglo IV/X, sólo se conocía hasta ahora un ejemplar de fuera de Córdoba: la estela funeraria procedente de Almería, con el epitafio de un varón de origen árabe, de nisba al-Taqāfî, fallecido en el año 312/924 ${ }^{47}$. A ella hay que unir esta estela funeraria de Madrid, con fecha expresa del 308/921, con la que asciende a tres el nú-

45 Así se puede constatar en los enterramientos de primera época emiral de la Plaza de la Marina, en Málaga (Peral Bejarano, "Excavación y estudio de los cementerios urbanos andalusíes. Estado de la cuestión”, p. 18), en los de la necrópolis mixta, de musulmanes y cristianos, de Marroquíes Bajos, en Jaén (Serrano Peña y Castillo Armenteros,"Las necrópolis musulmanas de Marroquíes Bajos (Jaén). Avance de las investigaciones arqueológicas", pp.93-120), en los de la maqbarat Bab Tulaytula de Zaragoza (Galve Izquierdo y Benavente Serrano, "La necrópolis islámica de la Puerta de Toledo de Zaragoza", pp. 383-390; Galve Izquierdo, "Necrópolis islámica de la Puerta de Toledo (Zaragoza): nuevas excavaciones", pp. 125-126), en los de la calle Herrerías, en Tudela, excavados entre 2005 y 2006 (Bienes, "Tudela islámica", pp. 211-213), o el existente en el Tolmo de Minateda, en Hellín (Albacete) (Gutiérrez Lloret, "La islamización de Tudmīr", pp. 296-299).

${ }^{46}$ Martínez Núñez, "Epigrafía funeraria en al-Andalus", pp. 183-185.

47 Ocaña Jiménez, Repertorio de las inscripciones árabes de Almería, pp. 1-2 y 127128, $\mathrm{n}^{\circ}$ 1; Lirola, "El testimonio del mármol: las inscripciones árabes como fuentes de información", p. 237. Hay otras dos inscripciones más que han sido datadas en este periodo del final del emirato, aunque carecen de fecha expresa: una que procede de Évora (Portugal), y conmemora la reconstrucción de la mencionada ciudad, se le ha adjudicado la fecha del 302/914-15; (Borges, "Duas inscrições árabes inéditas no Museu de Évora", pp. 3-7; Martínez Núñez, "Al-Andalus y la documentación epígrafica”, p. 94), y otra funeraria procedente de Sagunto, que ha sido datada entre los años 286 y 317 H. (Barceló, "Lápida funeraria de Murbāțir (Sagunt, segle X)"; Barceló, "El cúfico andalusí de «provincias» durante el califato (300-403/912-1013)", p. 174). 
mero de epitafios de cronología emiral, y que hayan conservado la data, hallados fuera de Córdoba. Además, es el segundo en antigüedad de los tres, pues el más arcaico de ellos es el procedente de Pechina (Almería), que se conserva en el Museo de Málaga y contiene el epitafio de un varón, de nisba al-Umawī, fallecido en el año 239/85448.

En tercer lugar, el interés se acrecienta si a lo anteriormente expuesto añadimos las características de talla, con labra en relieve, y los rasgos textuales. Tanto el cúfico de esta estela, tallado en relieve, como el formulario que presenta, con todos los elementos típicos de los epitafios de zonas urbanas, asemejan este epitafio a los procedentes de Córdoba y de Almería y pueden indicar la existencia en Madrid de un cementerio musulmán urbano de cierta entidad durante la etapa del emirato, remitiendo a un personaje relevante, bien por la preeminencia económica o por el prestigio social. En relación a esto, y a pesar de que siempre se ha señalado la importancia de la presencia beréber en el poblamiento de Madrid, dominado por el linaje de los Banū Sālim, de la tribu Mașmūda ${ }^{49}$, ni el antropónimo de la lápida ni las características formales o textuales permiten vislumbrar ningún rasgo beréber del difunto.

Es interesante destacar ese carácter urbano al que apuntan las características de la lápida pues, como es sabido por el relato de al-Rāzíi ${ }^{50}$, Madrid fue fundado como hisn por el emir omeya Muhammad I y las fuentes árabes lo designan indistintamente como hiṣn y como madina ${ }^{51}$, al igual que sucede en el caso de otros enclaves, como la Orihuela del pacto de Tudmīr ${ }^{52}$. C. Mazzoli-Guintard sostiene que el hisn Maŷrìt

48 Acién y Martínez, Catálogo de las inscripciones árabes del Museo de Málaga, p. $19, \mathrm{n}^{\circ} 1$, lám. I; Ocaña Jiménez, Repertorio de las inscripciones árabes, $\mathrm{n}^{\circ} 114$, lám. XLIX b; Martínez Núñez, Epigrafia árabe, pp. 59-60, nº 7.

49 Manzano Moreno, La frontera de al-Andalus en época de los omeyas, pp. 139 y ss.; Felipe, Identidad y onomástica de los beréberes de al-Andalus, pp. 220-224; MazzoliGuintard, "La fundación de Madrid", p. 18.

${ }^{50}$ El cronista al-Rāzī narra la fundación de Maŷriṭ por el emir omeya Muhammad I y refiere su interés por el bienestar de los musulmanes, preocupándose de consolidar y pro-

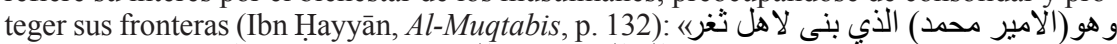
/ ط él (el emir Muhammad) fue el que construyó para la gente de la frontera de Toledo el castillo de Talamanca, el castillo de Madrid y el castillo de Peñafora».

${ }^{51}$ Mazzoli-Guintard, "La fundación de Madrid", pp. 22-23.

${ }^{52}$ Martínez Núñez, "Estelas funerarias de época califal”, p. 75. 
hubo de convertirse en una «madīna pequeña», así la designaba al-Idrīsī, tras la instauración del califato ${ }^{53}$, aunque esa evolución bien pudo tener lugar a finales del emirato. En cualquier caso, lo cierto es que la fundación de Madrid se inscribe en un proceso de urbanización que afecta a todo al-Andalus durante el siglo IX y que el núcleo primitivo se ubicaba en el emplazamiento de lo que hoy es el barrio de la Almudena, cerca del Palacio Real ${ }^{54}$, precisamente la zona de donde parece proceder la estela funeraria objeto de este estudio.

Sin embargo, y aunque los datos relativos al hallazgo no sean precisos, ese no parece que fuera el lugar de ubicación originaria de la lápida, que habría sido removida, sin que podamos determinar si fue también trasladada. La documentación histórica sitúa la necrópolis musulmana de Madrid extramuros y en el sector sureste de la plaza de Oriente aunque, como se ha planteado ${ }^{55}$, los pozos y silos hallados en las excavaciones de esa zona, atribuibles cronológicamente a la primera época de ocupación islámica, invalidan parcialmente esa localización y desplazan su localización más al norte, cerca de la Torre de los Huesos de la muralla cristiana, llamada así por la proximidad del cementerio ${ }^{56}$. Sea como fuere, lo destacable es que no se conocían restos arqueológicos que atestiguaran la existencia de la necrópolis musulmana ${ }^{57}$ hasta la localización de esta estela.

${ }^{53}$ Mazzoli-Guintard, Madrid, petite ville de l'Islam médiéval (IXe-XXIe siècles), pp. 60-65; Mazzoli-Guintard, "La fundación de Madrid", p. 23.

${ }_{54}$ Sobre el Madrid islámico, su fundación, su extensión y las distintas hipótesis sobre la cronología de los recintos fortificados, se pueden consultar distintas monografías: Valdés Fernández, "El Madrid islámico. Notas para una discusión arqueológica"; Mazzoli-Guintard, Madrid; Mazzoli-Guintard, "La fundación de Madrid"; Castellanos Oñate, "La medina de Maŷrit"; Retuerce Velasco, "Testimonios materiales del Madrid andalusís", pp. 81-116.

55 Castellanos Oñate, "La medina de Maŷrit", p. 32; Andréu Mediero, "La arqueología como determinante", pp. 42-44, 48.

${ }_{56}$ En unas excavaciones realizadas el año 2006 en la calle Toledo, $n^{\circ}$ 68, no lejos del Palacio Real, se localizó una amplia necrópolis islámica, con cuarenta y seis tumbas, que se prolongaría por la Plaza de la Cebada y por la calle Humilladero hasta la Puerta de Moros, abarcando una cronología de los siglos X al XV: Murillo, "Registro estratigráfico de una necrópolis musulmana en la calle Toledo, 68", pp. 89-98.

57 Andréu Mediero, "La arqueología como determinante", p. 48. La verdad es que son muy escasos los vestigios de época islámica que han llegado a nuestros días y ello se ha achacado a la decisión de Felipe II de trasladar la corte a Madrid y la consecuente actividad edilicia, con la construcción de casas palaciegas sobre demoliciones de otros edificios preexistentes: Andréu Mediero, "La arqueología como determinante", p. 40. 
Por último, y a pesar de que la talla en relieve y los elementos del formulario coincidan con los de las estelas funerarias de Córdoba, de Pechina y de Almería y remitan a enterramientos de zonas urbanas, el aspecto muy arcaizante y tosco de la grafía y el contenido inusual de las fórmulas de cierre, que la diferencian de los mencionados ejemplares de cronología emiral, inducen a plantear la posibilidad de que esta estela fuese realizada en algún taller local o, en cualquier caso, en algún centro ajeno a los que producían las lápidas funerarias en la capital omeya.

\section{Bibliografía}

Acién Almansa, Manuel y Martínez Núñez, Ma Antonia, Catálogo de las inscripciones árabes del Museo de Málaga, Madrid, Ministerio de Cultura, 1982.

Aguirre Sádaba, Javier, "Epitafios hispanomusulmanes de Arjona", Al-Qanțara, 19, 1 (1998), pp. 161-181.

Andréu Mediero, Esther, "La arqueología como determinante para el conocimiento del origen de Madrid", en Daniel Gil Flores (ed.), De Maŷrìt a Madrid. Madrid y los árabes, del siglo IX al siglo XXI, Barcelona-Madrid, LunwergCasa Árabe, 2011, pp. 40-53.

Arendonk, C. Van, "Salām", en Encyclopédie de l'Islam. Nouvelle Édition, Leiden, Brill, 1995, VIII, pp. 947-949.

Barceló, Carmen, "Estructura textual de los epitafios andalusíes (siglos IX-XIII)", en Homenaje a Manuel Ocaña Jiménez, Córdoba, Junta de Andalucía-Consejería de Cultura, 1990, pp. 41-54.

Barceló, Carmen, La escritura árabe en el país valenciano. Inscripciones monumentales, Valencia, Universidad, 1998, 2 vols.

Barceló, Carmen, "Lápida funeraria de Murbāṭir (Sagunt, segle X)", Studia Philologica Valentina (Epigrafies. Homenatge a Josep Corell), 5, 2 (2001), pp. 169-177.

Barceló, Carmen, "El cúfico andalusí de «provincias» durante el califato (300403/912-1013)", Cuadernos de Madinat al-Zahrā', 5 (2004), pp. 173-197.

Barceló, Carmen, "Las inscripciones omeyas de la alcazaba de Mérida", Arqueología y Territorio Medieval, 11, 1 (2004), pp. 59-78.

Bienes, Juan José, "Tudela islámica", en Philippe Sénac (ed.), Villa 2. Villes et campagnes de Tarraconaise et d'al-Andalus ( $V I^{e}-X I^{e}$ siècle): la transition, Toulouse, CNRS-Université de Toulouse-Le Mirail, 2007, pp. 199-218.

Borges, A. Goulart de Melo, "Duas inscrições árabes inéditas no Museu de Évora”, A cidade de Évora, 67-68 (1987), pp. 3-13. 
Castellanos Oñate, José Manuel, "La medina de Maŷrīt", en Daniel Gil Flores (ed.), De Maŷrìt a Madrid. Madrid y los árabes, del siglo IX al siglo XXI, Barcelona-Madrid, Lunwerg-Casa Árabe, 2011, pp. 30-39.

Doménech Belda, Carolina y López Seguí, Eduardo, "Los alifatos sobre hueso: un ejemplar del casco antiguo de Alicante", Lvcentvm, XXVII (2008), pp. 243-257.

Felipe, Helena de, Identidad y onomástica de los beréberes de al-Andalus, Madrid, CSIC, 1997.

Galve Izquierdo, Pilar, "Necrópolis islámica de la Puerta de Toledo (Zaragoza): nuevas excavaciones", en María Paz Torres Palomo y Manuel Acién Almansa (eds.), Estudios sobre cementerios islámicos andalusíes, Málaga, Universidad, 1995, pp. 117-136.

Galve Izquierdo, Pilar y Benavente Serrano, José A., "La necrópolis islámica de la Puerta de Toledo de Zaragoza", en Actas del III Congreso de Arqueología Medieval Española, t. II, Comunicaciones, Oviedo, Universidad, 1992, pp. 383-390.

Gutiérrez Lloret, Sonia, "La islamización de Tudmīr”, en Philippe Sénac (ed.), Villa 2. Villes et campagnes de Tarraconaise et d'al-Andalus (VI'-XIe siècle): la transition, Toulouse, CNRS-Université de Toulouse-Le Mirail, 2007, pp. 275-318.

Ibn Hayyān al-Andalusī, Kitāb al-Muqtabis min abnā' ahl al-Andalus, Maḥmūd 'Alī Makkī (ed.), Beirut, Dār al-Kitāb al-'Arabī, 1973.

Ibn Hazm al-Qurțubī, Ŷamharat ansāb al-'arab, 'Abd al-Salām Muhammad Hārūn (ed. crítica), El Cairo, Dār al-Ma ārif, 1982, $5^{\text {a }}$ ed.

Lévi-Provençal, Évariste, Inscriptions arabes d'Espagne, París-Leiden, LaroseBrill, 1931, 2 vols.

Lirola, Jorge, "El testimonio del mármol: las inscripciones árabes como fuentes de información", en Ángela Suárez Márquez (coord.), La Alcazaba. Fragmentos para una historia de Almería, Almería, Junta de Andalucía-Consejería de Cultura, 2005, pp. 237-250.

Manzano Moreno, Eduardo, La frontera de al-Andalus en época de los omeyas, Madrid, CSIC, 1991.

Martínez Núñez, Ma Antonia, "La epigrafía del Salón de 'Abd al-Raḥmān III”, en Antonio Vallejo Triano (ed.), Madīnat al-Zahrā'. El Salón de 'Abd al-Rahmān III, Córdoba, Junta de Andalucía-Consejería de Cultura, 1995, pp. 107152.

Martínez Núñez, Ma Antonia, "Al-Andalus y la documentación epigráfica”, en Adel Sidarus (ed.), Fontes da Hístoria de al-Andalus e do Gharb, Lisboa, Centro de Estudos Africanos e Asiáticos-Institutoã de Investigação Científica Tropical, 2000, pp. 89-115.

Martínez Núñez, $M^{a}$ Antonia, "Estelas funerarias de época califal aparecidas en Orihuela (Alicante)", Al-Qantara, 22, 1 (2001), pp. 45-76. 
Martínez Núñez, $\mathrm{M}^{\mathrm{a}}$ Antonia, "Mujeres y élites sociales en al-Andalus a través de la documentación epigráfica", en $\mathrm{M}^{\mathrm{a}}$ Isabel Calero Secall (coord.), Mujeres y sociedad islámica: una visión plural, Málaga, Universidad, 2006, pp. 287328.

Martínez Núñez, Ma Antonia, Epigrafía árabe. Catálogo del Gabinete de Antigüedades, Isabel Rodríguez Casanova y Alberto Canto García (colaboradores), Madrid, Real Academia de la Historia, 2008.

Martínez Núñez, $\mathrm{M}^{\mathrm{a}}$ Antonia, "Epigrafía árabe e historia de al-Andalus: nuevos hallazgos y datos", Xelb. 9 (2009) [Actas do $6^{\circ}$ Encontro de Arqueologia do Algarve. O Gharb al-Andalus: sintesis e perspectivas de estudo. Homenagem a José Luís de Matos (Silves, 23, 24 e 25 de Outoubro 2008)], pp. 41-53.

Martínez Núñez, $M^{a}$ Antonia, "Estela funeraria de cronología califal aparecida en Mengíbar (Jaén)", Cuadernos de Madīnat al-Zahrā', 7 (2010), pp. 83-94.

Martínez Núñez, Ma Antonia, "Epigrafía funeraria en al-Andalus (siglos IX-XII)", Mélanges de la Casa de Velázquez, nouvelle série, 41, 1 (2011), pp. 181-209.

Martínez Núñez, Ma Antonia, Epigrafía árabe del Museo Arqueológico Provincial de Badajoz, Badajoz, Museo Arqueológico Provincial-Junta de Extremadura, 2013.

Mazzoli-Guintard, Christine, Madrid, petite ville de l'Islam médiéval (IX'e-XXI siècles), Rennes, Presses Universitaires de Rennes, 2009. Ed. española: $M a-$ drid, pequeña ciudad de al-Andalus (siglos IX-XXI), Madrid, Almudayna, 2011.

Mazzoli-Guintard, Christine, "La fundación de Madrid", en Daniel Gil Flores (ed.), De Maŷrịt a Madrid. Madrid y los árabes, del siglo IX al siglo XXI, Barcelona-Madrid, Lunwerg-Casa Árabe, 2011, pp. 18-29.

Murillo, José Ignacio, "Registro estratigráfico de una necrópolis musulmana en la calle Toledo, 68”, en Actas de las III Jornadas de Patrimonio Arqueológico de la Comunidad de Madrid, Madrid, Comunidad de Madrid-Dirección General de Patrimonio Histórico, 2007, pp. 89-98.

Ocaña Jiménez, Manuel, Repertorio de inscripciones árabes de Almería, MadridGranada, CSIC, 1964.

Ocaña Jiménez, Manuel, El cúfico hispano y su evolución, Madrid, Instituto Hispano-Árabe de Cultura, 1970.

Ocaña Jiménez, Manuel, Nuevas tablas de conversión de datas islámicas a cristianas y viceversa, estructuradas para concordar, día por día, años completos, Madrid, Instituto Hispano-Árabe de Cultura, 1981.

Ory, Solange, "Les graffiti umayyades de 'Ayn Garr”, Bulletin du Musée de Beyrouth, 20 (1967), pp. 97-148.

Ory, Solange, “Aspects religieux des textes épigraphiques du début de l'Islam", Revue du monde musulman et de la Méditerranée, 58 (1990), pp. 30-39.

Peral Bejarano, Carmen, "Excavación y estudio de los cementerios urbanos andalusíes. Estado de la cuestión”, en Manuel Acién y Ma Paz Torres (eds.), Es- 
tudios sobre cementerios islámicos andalusies, Málaga, Universidad, 1995, pp. 11-36.

Retuerce Velasco, Manuel, "Testimonios materiales del Madrid andalusí”, en Testimonios del Madrid Medieval. El Madrid musulmán, Madrid, Ayuntamiento, 2004, pp. 81-116.

Serrano Peña, José Luis y Castillo Armenteros, Juan Carlos, “Las necrópolis musulmanas de Marroquíes Bajos (Jaén). Avance de las investigaciones arqueológicas", Arqueología y Territorio Medieval, 7 (2000), pp. 93-120.

Sourdel-Thomine, Janine, "Inscriptions et graffiti arabes d'époque umayyade. À propos de quelques publications récentes", Revue des études islamiques, 32, 1 (1964), pp. 115-120.

Terés, Elías, “Antroponimia hispano-árabe (reflejada por las fuentes hispano-romances) (II parte)", Jorge Aguadé, Carmen Barceló y Federico Corriente (ed.), Anaquel de Estudios árabes, 3 (1992), pp. 13-34.

Valdés Fernández, Fernando, "El Madrid islámico. Notas para una discusión arqueológica", en Fernando Valdés Fernández (coord.), Maŷrìt. Estudios de arqueología medieval madrileña, Madrid, Polifemo Ediciones, 1992, pp. 141-180.

Zozaya Stabel-Hansen, Juan, "Os inscrit", en Les Andalousies, de Damas à Cordoue, París, Institut du Monde Arabe, 2000, p. 93.

Recibido: $02 / 02 / 2014$ Aceptado: 16/02/2015 